\title{
COAGULOPATHY IN NEURO TRAUMA - A PROSPECTIVE ANALYSIS OF THE INCIDENCE AND CAUSES OF COAGULOPATHY IN PATIENTS WITH PURE NEURO TRAUMA AND MIXED TRAUMA ADMITTED TO THE NATIONAL HOSPITAL SRI LANKA
}

\author{
*Jayawickrama D.T ${ }^{l}$, Hapuarachchi $S^{2}$. \\ Senior Registrar National Hospital of Sri Lanka ${ }^{1}$, Consultant Anaesthetist, Neuro Surgical \\ Unit, National Hospital, Sri Lanka ${ }^{2}$ \\ *Corresponding author:doctorj@sltnet.lk
}

Key words: neurotrauma, coagulopathy

\begin{abstract}
Background: Coagulopathy is probably universal in patients with severe trauma. The pathogenesis of coagulopathy in trauma patients is complex. The precise cause is difficult to identify and is likely to be multifactorial ${ }^{4,1}$. Clotting factor and platelet loss associated with vascular disruption as well as by intravascular consumption of clotting factors associated with massive endothelial damage are implicated in the coagulopathy in severe trauma patients. Coagulopathy in trauma patients is exacerbated by dilution, acidosis and hypothermia. Coagulopathy also occurs when brain or fat embolism leads to disseminated intravascular coagulation, hepatic injury leads to synthetic insufficiency or renal damage leads to uraemia and platelet dysfunction.
\end{abstract}

Method: During the study period 100 patients with moderate to severe trauma were admitted to the neuro surgical intensive care units (ICU) in National Hospital, Sri Lanka and were analysed in the study sample. The two groups were pure neuro trauma and mixed trauma (neuro trauma and other injuries).

A questionnaire was kept at the three neuro surgical ICUs at NHSL, to be attached to the notes of all the patients admitted to the neurosurgical ICU following trauma. These were filled by the ICU doctors as the results came in.

Results: During the study period 100 patients with moderate to severe trauma were admitted to the Neuro Surgical ICU in National Hospital, Sri Lanka and were analysed in the study sample. The two groups were pure neuro trauma and mixed trauma (neuro trauma and other injuries).

For the purpose of the study each patient was assessed for the 1 st 24 hours in the Neuro Surgical ICU. Coagulopathy was taken as positive if INR $>1.5$ or platelet count $<100,000$. Acidosis was taken as $\mathrm{pH}<7.35$ and hypothermia was taken as temperature less than $34{ }^{0} \mathrm{C}$. Deranged renal and liver function test was considered as dysfunction.

Activated partial thromboplastin time (APTT) was not an available test in the NHSL laboratory.

Conclusion: Results from this audit did not show a significant difference between the coagulopathy associated with pure neuro trauma and mixed trauma. A slight increase in trend in coagulopathy was seen in pure neuro trauma group compared with mixed trauma.

There was no significant difference between the presence of a particular factor favoring coagulopathy and the presence of coagulopathy in the two study groups. The coagulopathy in the above two groups is likely to be multi factorial.

Coagulopathy is a common complication in trauma. Several factors have been shown to contribute to this disease state. Hypovolaemia resulting in overzealous crystalloid resuscitation, and massive blood transfusion can lead to dilutional coagulopathy. Severe haemorrhage can result in consumption of clotting factors resulting in consumption coagulopathy. In addition acidosis, is a common occurrence in trauma patients due to tissue hypoxia. 
Hypothermia has also been implicated. Coagulation defects may be due to brain tissue or fat embolism leading to disseminated intravascular coagulopathy. Hepatic injury can lead to a reduction in the synthesis of cloting factors. Renal damage can cause platelet dysfunction. In neuro trauma patients with intra cerebral haemorrhage coagulation defects may be due to both coagulation and platelet defects. Most elderly patients are on asprin and clopidogrel and they may already have a platelet defect at the time of admission.

This study was carried out to find the incidence of coagulopathy in patients with pure neuro- trauma, the incidence of coagulopathy in patients with mixed trauma and to analyse the possible causes of coagulopathy in the above two groups. Also depending on the findings to improve the management of patients with neuro and mixed trauma.

The study population consisted of patients who were admitted to the neurosurgical intensive care units following moderate to severe trauma. These patients included patients with pure neuro trauma as well as patients with mixed trauma over a given period of time. Total number of patients was 100.

\section{Material and Methods}

During the study period 100 patients with moderate to severe trauma were admitted to the neuro surgical ICUs in the National Hospital, Sri Lanka and were analysed in the study sample. The two groups were pure neuro trauma and mixed trauma (neuro trauma and other injuries). A questionnaire was kept at the three neuro surgical ICUs at NHSL, to be attached to the notes of all the patients admitted to the ICU following trauma. These were filled by the ICU doctors as the results came in. The questionnaire was structured to obtain the following information. Patient's age, sex and weight, type of injury, transfusions carried out, history of anti-platelet therapy and other organ disease, presence of hypothermia and acidosis, clotting profile and platelet count.

The usual management of the patients in the ICU was not changed. Any personnel details which will identify the patients were not requested. Confidentiality was maintained. Due to these reasons ethical clearance was not sought. Coagulopathy was considered as present if INR $>1.5$ or the platelet count is < $100,000 \mathrm{~mm}^{3}$. The possible causes for each patient with coagulopathy was tabulated and analysed.

For the purpose of the study each patient was assessed for the first 24 hours in the neuro surgical ICU. Coagulopathy was taken as positive if INR $>1.5$ or platelet count $<$ 100,000. Acidosis was taken as $\mathrm{pH}<7.35$ and hypothermia was taken as temperature less than $34^{\circ} \mathrm{C}$. Deranged renal and liver function test was considered as dysfunction.

Activated partial thromboplastin time (APTT) was not an available test in the NHSL laboratory.

Data were entered and analysed by using Statistical Package for Social Sciences (SPSS Inc, Chicago, USA) computer program (version 17.0). Chi square test was used to compare categorical variables among study group to test significance, the Yates corrected test was used when expected value is $<5$ of the relevant variable. The $p$ values of $<0.05$ were considered statistically significant. 
Results :

Table 1: Coagulopathy status by study group of trauma

\begin{tabular}{|c|c|c|c|c|c|c|c|c|}
\hline \multirow{3}{*}{$\begin{array}{l}\text { Status of } \\
\text { Coagulopathy }\end{array}$} & \multicolumn{4}{|c|}{ Study group of trauma } & \multirow{2}{*}{\multicolumn{2}{|c|}{ Total }} & \multirow{2}{*}{\multicolumn{2}{|c|}{$\begin{array}{l}\text { Significance } \\
(\mathbf{d f}=\mathbf{1})\end{array}$}} \\
\hline & \multicolumn{2}{|c|}{$\begin{array}{l}\text { Neuro } \\
\text { Trauma }\end{array}$} & \multicolumn{2}{|c|}{$\begin{array}{l}\text { Mixed } \\
\text { trauma }\end{array}$} & & & & \\
\hline & $\mathrm{n}$ & $\%$ & $\mathrm{n}$ & $\%$ & $\mathrm{n}$ & $\%$ & $\chi^{2}$ & p-value \\
\hline Positive & 14 & 53.8 & 12 & 46.2 & 26 & 100.0 & 3.23 & $0.07, \mathrm{NS}$ \\
\hline Negative & 54 & 73.0 & 20 & 27.0 & 74 & 100.0 & & \\
\hline Total & 68 & 68.0 & 32 & 32.0 & 100 & $\mathbf{1 0 0 . 0}$ & & \\
\hline
\end{tabular}

NS=Not Significant

Among positive, a slightly increase $(53.8 \%)$ trend was seen in pure neuro trauma patients compared to the mixed trauma group. The percentage of negatives in neuro trauma group was higher than in mixed trauma.

There was no statistically significant difference in the presence of Coagulopathy in the two study groups.

Reported Coagulopathy according to selected Characteristics $(\mathbf{n}=26)$

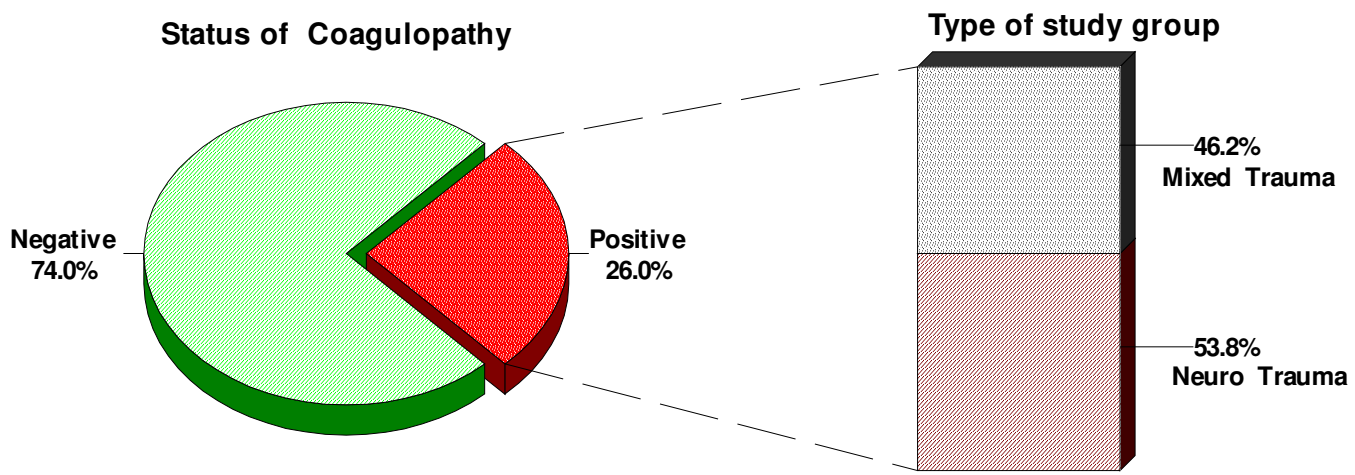

Figure 1 Coagulopathy distribution of patients by study group

As presented in Figure 1, of the positive patients' in the study sample 53.8\% was from pure neuro trauma group and $46.2 \%$ was from the mixed trauma group.

Table 2: $\quad$ Massive transfusion distribution by study groups

\begin{tabular}{|c|c|c|c|c|c|c|c|c|}
\hline \multirow{3}{*}{$\begin{array}{l}\text { Massive } \\
\text { transfusion }\end{array}$} & \multicolumn{4}{|c|}{ Study group of trauma } & \multirow{2}{*}{\multicolumn{2}{|c|}{ Total }} & \multirow{2}{*}{\multicolumn{2}{|c|}{$\begin{array}{l}\text { Significance } \\
(\mathbf{d f}=\mathbf{1})\end{array}$}} \\
\hline & \multicolumn{2}{|c|}{$\begin{array}{l}\text { Neuro } \\
\text { Trauma }\end{array}$} & \multicolumn{2}{|c|}{$\begin{array}{l}\text { Mixed } \\
\text { trauma }\end{array}$} & & & & \\
\hline & $\mathrm{n}$ & $\%$ & $\mathrm{n}$ & $\%$ & $\mathrm{n}$ & $\%$ & $\chi^{2}$ & p-value \\
\hline Present & 4 & 33.3 & 8 & 66.7 & 12 & 100.0 & 3.77 & $0.05, \mathrm{NS}$ \\
\hline Not present & 10 & 71.4 & 4 & 28.6 & 14 & 100.0 & & \\
\hline Total & 14 & 53.8 & 12 & 46.2 & 26 & 100.0 & & \\
\hline
\end{tabular}

NS=Not Significant

In the group who were positive for coagulopathy a low percentage following massive transfusion $(33.3 \%)$ was noted in neuro trauma than mixed trauma. There was no statistically significant association $(\mathrm{p}=0.05)$ between coagulopathy and massive transfusion in the two study groups. 
Table 3: $\quad$ Acidosis distribution by study groups

\begin{tabular}{|c|c|c|c|c|c|c|c|c|}
\hline \multirow{3}{*}{ Acidosis } & \multicolumn{4}{|c|}{ Study group of trauma } & \multirow{2}{*}{\multicolumn{2}{|c|}{ Total }} & \multirow{2}{*}{\multicolumn{2}{|c|}{$\begin{array}{l}\text { Significance } \\
(\mathbf{d f}=1)\end{array}$}} \\
\hline & \multicolumn{2}{|c|}{$\begin{array}{l}\text { Neuro } \\
\text { Trauma }\end{array}$} & \multicolumn{2}{|c|}{$\begin{array}{l}\text { Mixed } \\
\text { trauma }\end{array}$} & & & & \\
\hline & $\mathrm{n}$ & $\%$ & $\mathrm{n}$ & $\%$ & $\mathrm{n}$ & $\%$ & $\chi^{2}$ & p-value \\
\hline Present & 4 & 40.0 & 6 & 60.0 & 10 & 100.0 & $0.51^{*}$ & $0.47, \mathrm{NS}$ \\
\hline Not present & 10 & 62.5 & 6 & 37.5 & 16 & 100.0 & & \\
\hline Total & 14 & 53.8 & 12 & 46.2 & 26 & 100.0 & & \\
\hline
\end{tabular}

NS=Not Significant

* Yates corrected test was applied

In the patient group who were positive for coagulopathy $40 \%$ from the pure neuro trauma group had acidosis and a higher percentage (60\%) with acidosis was seen among the mixed trauma group.

There was no significant difference between coagulopathy and acidosis in the two study groups.

Table 4: $\quad$ Hypothermia distribution by study groups

\begin{tabular}{|c|c|c|c|c|c|c|c|c|}
\hline \multirow{3}{*}{ Hypothermia } & \multicolumn{4}{|c|}{ Study group of trauma } & \multirow{2}{*}{\multicolumn{2}{|c|}{ Total }} & \multirow{2}{*}{\multicolumn{2}{|c|}{$\begin{array}{l}\text { Significance } \\
(\mathbf{d f}=\mathbf{1})\end{array}$}} \\
\hline & \multicolumn{2}{|c|}{$\begin{array}{l}\text { Neuro } \\
\text { Trauma }\end{array}$} & \multicolumn{2}{|c|}{$\begin{array}{l}\text { Mixed } \\
\text { trauma }\end{array}$} & & & & \\
\hline & $\mathrm{n}$ & $\%$ & $\mathrm{n}$ & $\%$ & $\mathrm{n}$ & $\%$ & $\chi^{2}$ & $\mathrm{p}$-value \\
\hline Present & 2 & 33.3 & 4 & 66.7 & 6 & 100.0 & $0.47 *$ & $0.49, \mathrm{NS}$ \\
\hline Not present & 12 & 60.0 & 8 & 40.0 & 20 & 100.0 & & \\
\hline Total & 14 & 53.8 & 12 & 46.2 & 26 & 100.0 & & \\
\hline
\end{tabular}

NS=Not Significant,$*$ Yates corrected test was applied

Of the coagulopathy positive patients $66.7 \%$ of the mixed group had hypothermia where as $33.3 \%$ of neuro trauma group had hypothermia. No significant difference was seen in the two study groups associating hypothermia and coagulopathy.

Previous coagulopathy and anti-platelet therapy were not present in both groups.

Table 5: $\quad$ Renal/liver dysfunction status of patients by study groups

\begin{tabular}{|c|c|c|c|c|c|c|c|c|}
\hline \multirow{3}{*}{$\begin{array}{l}\text { Renal/liver } \\
\text { dysfunction }\end{array}$} & \multicolumn{4}{|c|}{ Study group of trauma } & \multirow{2}{*}{\multicolumn{2}{|c|}{ Total }} & \multirow{2}{*}{\multicolumn{2}{|c|}{$\begin{array}{l}\text { Significance } \\
(\mathbf{d f}=1)\end{array}$}} \\
\hline & \multicolumn{2}{|c|}{$\begin{array}{l}\text { Neuro } \\
\text { Trauma }\end{array}$} & \multicolumn{2}{|c|}{$\begin{array}{l}\text { Mixed } \\
\text { trauma }\end{array}$} & & & & \\
\hline & $\mathrm{n}$ & $\%$ & $\mathrm{n}$ & $\%$ & $\mathrm{n}$ & $\%$ & $\chi^{2}$ & $\mathrm{p}$-value \\
\hline Present & 3 & 42.9 & 4 & 57.1 & 7 & 100.0 & $0.06^{*}$ & $0.8, \mathrm{NS}$ \\
\hline Not present & 11 & 57.9 & 8 & 42.1 & 19 & 100.0 & & \\
\hline Total & 14 & 53.8 & 12 & 46.2 & 26 & 100.0 & & \\
\hline
\end{tabular}

NS=Not Significant

* Yates corrected test was applied

Of the coagulopathy positive patients $57.1 \%$ from the mixed group and $42.9 \%$ from the pure neuro trauma group had liver/renal dysfunction. No significant difference was seen in the two study groups associating liver/renal dysfunction and coagulopathy. 
Table 6: Relationship between status of the Coagulopathy and other associated factors of patients by study groups

\begin{tabular}{|c|c|c|c|c|c|c|c|c|}
\hline \multirow{3}{*}{$\begin{array}{l}\text { Status of the } \\
\text { Coagulopathy }\end{array}$} & \multicolumn{4}{|c|}{ Study group of trauma } & \multirow{2}{*}{\multicolumn{2}{|c|}{ Total }} & \multirow{2}{*}{\multicolumn{2}{|c|}{$\begin{array}{l}\text { Significance } \\
(\mathbf{d f}=\mathbf{1})\end{array}$}} \\
\hline & \multicolumn{2}{|c|}{$\begin{array}{l}\text { Neuro } \\
\text { Trauma }\end{array}$} & \multicolumn{2}{|c|}{$\begin{array}{l}\text { Mixed } \\
\text { trauma }\end{array}$} & & & & \\
\hline & $\mathrm{n}$ & $\%$ & $\mathrm{n}$ & $\%$ & $\mathrm{n}$ & $\%$ & $\chi^{2}$ & p-value \\
\hline \multicolumn{9}{|l|}{ Coagulopathy + } \\
\hline None & 7 & 26.9 & 3 & 11.5 & 10 & 38.5 & & \\
\hline Total & 14 & 53.8 & 12 & 46.2 & 26 & 100.0 & & \\
\hline \multicolumn{9}{|l|}{ Coagulopathy - } \\
\hline At least one** & 13 & 17.6 & 9 & 12.2 & 22 & 29.7 & 3.06 & $0.08, \mathrm{NS}$ \\
\hline None & 41 & 55.4 & 11 & 14.9 & 52 & 70.3 & & \\
\hline Total & 54 & 73.0 & 20 & 27.0 & 74 & $\mathbf{1 0 0 . 0}$ & & \\
\hline
\end{tabular}

NS=Not Significant

* Yates corrected test was applied

** massive transfusion, acidosis, hypothermia, previous coagulopathy, anti-platelet therapy, renal/liver dysfunction

Of the patients positive for coagulopathy $61.5 \%$ had at least one factor which would make them more susceptible for coagulopathy. Of the patients who did not have coagulopathy $29.7 \%$ had at least one factor favouring coagulopathy.

Figure 2

Relationship between Coagulopathy status and associated number of factors by neurotrauma and mixed trauma

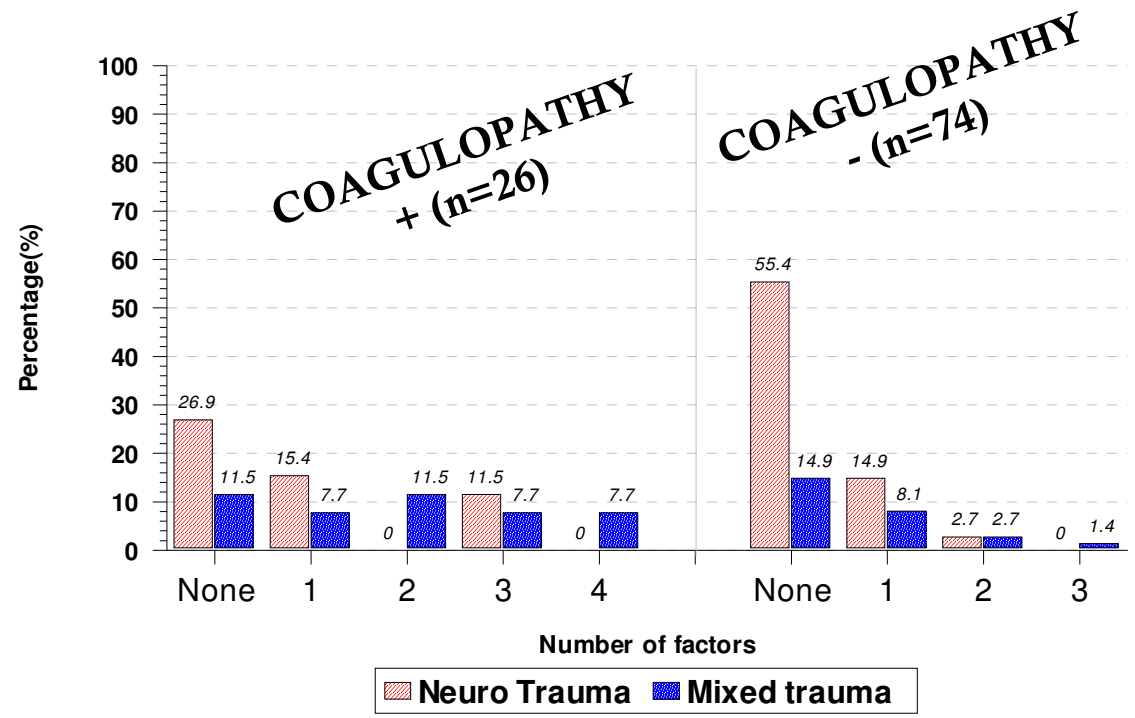

In patients with coagulopathy from the pure neuro trauma group $26.9 \%$ did not have any factors favouring coagulopathy except for the brain trauma itself, $11.5 \%$ from the mixed trauma group did not have any factor favoring coagulopathy except for the brain trauma itself.

These findings could have been affected by a number of factors: 
1. The neuro trauma patients who were taken for this study did not have a major injury to the other organs.

2. Different management approach with regard to resuscitation of these patients by the doctors in emergency treatment unit, operating theater and intensive care unit

3. The time delay for the blood/ blood components to be available for resuscitation.

4. Lack of facilities that are readily available during transfusion e.g. fluid warmers.

\section{Discussion:}

Acute coagulopathy of major trauma develops early in the post-injury phase. It is associated with increased transfusion requirements and poor outcomes ${ }^{3}$.

The early acute coagulopathy associated with traumatic injury is a multifactorial primary condition that results from a combination of shock, tissue injury-related thrombin generation

and the activation of anticoagulant and fibrinolytic pathways. The condition is influenced by environmental and therapeutic factors that contribute to acidaemia, hypothermia, dilution ${ }^{6}$, hypoperfusion and clotting factor consumption.

Clotting factor and platelet loss associated with vascular disruption as well as by intravascular consumption of clotting factors associated with massive endothelial damage are implicated in the coagulopathy in severe trauma patients. Coagulopathy also occurs when brain or fat embolism leads to disseminated intravascular coagulation, hepatic injury leads to synthetic insufficiency or renal damage leads to uraemia and platelet dysfunction.

Pre existing liver or renal dysfunction, chronic alcoholism, use of antiplatelet drugs or anticoagulants may also play a role in the coagulopathy in massive trauma patients.

Abnormalities of coagulopathy occur frequently in patients with massive neurotrauma. Exposure to thromboplastin which is abundant in the brain is an important factor in initiating coagulopathy in patients with head injury ${ }^{2}$.

The interaction between hypothermia, acidosis and coagulopathy known as the lethal triad often results in massive bleeding which is difficult to control. The coagulopathy was treated by correction of acid base disorder, hypothermia, replacement of clotting factors and other supportive therapy.

A number of terms have been proposed to describe the condition, which is distinct from disseminated intravascular coagulation, including acute traumatic coagulopathy, early coagulopathy of trauma, acute coagulopathy of trauma - shock and trauma induced coagulopathy ${ }^{5}$.

\section{Conclusion}

Results from this audit did not show a significant difference between the coagulopathy associated with pure neuro trauma and mixed trauma. A slight increase in trend in coagulopathy was seen in pure neuro trauma group compared with mixed trauma.

There was no significant difference between the presence of a particular factor favoring coagulopathy and the presence of coagulopathy in the two study groups. The coagulopathy in the above two groups is likely to be multi factorial. It is recommended to have guidelines/ protocols with regard to resuscitation of neuro trauma patients (including blood component therapy) with moderate to severe injury, and to update the medical staff who are involved in resuscitation in emergency treatment unit, Operating Theater and Intensive Care Unit, and to educate the above staff on the presence of coagulopathy in head injury patients and the likely responsible factors, with a view to improving patient management. 


\section{References}

1. Dirkman Daniel, Hank Alexander Hypothermia and acidosis synergistically impair coagulation in human whole blood, Anaesthesia and analgesia 2008:106(6) 1627- 1632

2. Saggar Vineet, S Mittal Rahey and Vyas, Haemostatic abnormalities in patients with closed head injuries and their role in predicting early mortality, Journal of neurotrauma 2009: 26(1),15

3. Karim Brohi, , Davenport Mitchell, Ross , Acute coagulopathy of trauma- mechanism identification and effect, Current opinion in critical care 2007: 13(6), 680-85

4. Rossaint Saphn - Coagulopathy and blood component transfusion in trauma, $\mathrm{Br} j$ Anaesth 2005: 95(2), 130-139

5. Management of bleeding following major trauma an updated European guideline, Critical Care; (14)

6. Wafaisade Arasch, Watzler Sebashan Drivers of acute coagulopathy after severe trauma, Emergency medicine Journal 2009; 10. 1136 